\title{
ЗНАЧЕННЯ РН-МЕТРІЇ В ДІАГНОСТИЦІ І ФОРМУВАННІ ПЕРСОНІФІКОВАНОГО КОМПЛЕКСНОГО ЛІКУВАННЯ ПАЦІЄНТА ПІСЛЯ ПІЛОРУСЗБЕРІГАЮЧОЇ ПАНКРЕАТОДУОДЕНАЛЬНОЇ РЕЗЕКЦІї
}

\author{
๑Л. С. Бабінець, І. В. Махніцька, Ю. Я. Коцаба
}

Тернопільський начіональний медичний університет імені І. Я. Горбачевського МОЗ України

РЕЗЮМЕ. Кислотозалежні захворювання складають значну частину гастроентерологічної патології. Точна діагностика та ефективно підібрана терапія визначають перебіг захворювання і прогноз пацієнта. На сьогодні оцінка секреторної функції шлунка із застосуванням рН-метрії $\epsilon$ найбільш інформативною і досконалою.

Мета - на клінічному прикладі продемонструвати діагностичну цінність використання рН-метрії при кислотозалежному поліморбідному стані пацієнта з метою визначення лікарської тактики.

Результати (клінічний випадок). Пацієнт С., 45 років, діагноз-інсулома головки підшлункової залози T2N0M0, II стадія, ІІа клінічна група, 10.04.2017р. - атипова резекція головки підшлункової залози з інсуломою.

При первинній внутрішньошлунковій рН-експрес-діагностиці встановлено виражену гіпоацидність: наявний дуоденогастроезофагельний рефлюкс на фоні тижневої відміни ІПП пантопразолу, який до цього тривало приймав пацієнт у дозі 20 мг 1 раз на добу. Повторне проведення внутрішньошлункової рН-метрії на тлі відміни пантопразолу протягом 1 міс. також показало результат на рівні вираженої гіпоацидності. Проте порівнюючи показники рН-метрії в динаміці ми встановили поступове зниження глибини гіпоацидності шлунка, покращення загального стану пацієнта, зменшення інтенсивності клінічної симптоматики.

Висновки. 1. Призначення протокольної терапії у хворих з кислотозалежними захворюваннями навіть при позитивному тесті на Н. pylori потребує додаткового визначення кислотності шляхом виконання внутрішньошлункової рН-експрес-діагностики.

2. Аналіз описаного клінічного випадку з виконанням рН-метрії підтвердив вищу діагностичну цінність дихального тесту на $H$. pylori, порівняно з виявленням позитивного антигена в калі.

3. Результат виконання рН-метрії у даному клінічному випадку став підґрунтям для відміни антисекреторного препарату пантопразолу.

КлючОВІ СлОВА: інсулома; кислотозалежні стани; шлунок; лікування.

Вступ. Кислотозалежні захворювання складають значну частину гастроентерологічної патології. Точна діагностика та ефективно підібрана терапія в кінцевому результаті визначають перебіг захворювання й прогноз пацієнта [4, 5]. За останні роки з'явилась удосконалена медична електронна техніка, яка суттєво розширила уявлення не тільки про стан кислотопродукувальної функції шлунка, а й про характер моторних порушень верхнього відділу ШКТ. На сьогодні оцінка секреторної функції шлунка із застосуванням рНметрії $є$ найбільш інформативною і досконалою. Внутрішньошлункова рН-метрія розглядається як фізіологічний метод, оскільки не впливає на роботу та умови функціонування шлунка, не стимулює секреторну функцію, не провокує появу патологічних рефлексів [3]. У практиці лікування за допомогою цього методу можна оцінити ефективність різних антацидних препаратів, а також нових і потужних інгібіторів шлункової секреції, в тому числі пролонгованої дії. Виконання внутрішньошлункової рН-метрії та ії ретельна оцінка $\epsilon$ дуже цінними при вирішенні питань лікарської тактики у складних і невизначених випадках. До таких проблемних для лікаря ситуацій належить виявлення у пацієнта інсуломи $[1,6]$.
Інсулома - гормонально-активна пухлина, яка розвивається з базофільних інсулоцитів (бета-клітин) панкреатичних острівців і продукує надлишкову кількість інсуліну, що проявляється нападами гіпоглікемічних симптомів. Уперше інсулому в 1902 р. описав Ніколс, коли виявив цю пухлину при автопсії. Через 2 роки Л. В. Соболєв виявив її у пацієнта з цукровим діабетом та описав як гіпертрофію і гіперплазію острівцевих клітин. У 85-90 \% випадків інсулома $\epsilon$ солітарною доброякісною пухлиною, 10-15 \% пухлин множинні, 1 \% - розташовуються поза підшлунковою залозою (ворота селезінки, печінка, стінка дванадцятипалої кишки або шлунка, сальник тощо). Таке розташування і гормональна активність інсуломи часто призводить до довготривалої клінічної невизначеності щодо діагнозу і лікувальної тактики $[2,6]$.

Мета - на клінічному прикладі продемонструвати діагностичну цінність використання рН-метрії при кислотозалежному поліморбідному стані пацієнта з метою визначення лікарської тактики.

Клінічний випадок. Пацієнт С., 45 років. У серпні 2016 р. вперше відмітив напад гіпоглікемії. Після клінічного обстеження було встановлено діагноз - інсулома голівки підшлункової залози 
Огляди літератури, оригінальні дослідження, погляд на проблему, випадок з практики, короткі повідомлення T2N0M0, II стадія, ІІа клінічна група. 10.04.2017 р.була здійснена атипова резекція головки підшлункової залози з інсуломою. Стан тимчасово покращився, але в серпні 2017 р. знову почав від-

мічати напади гіпоглікемії.

У квітні 2018 р. було виконано No-touch пілорусзберігаючу панкреатодуоденальну резекцію за Nagai (рис. 1).

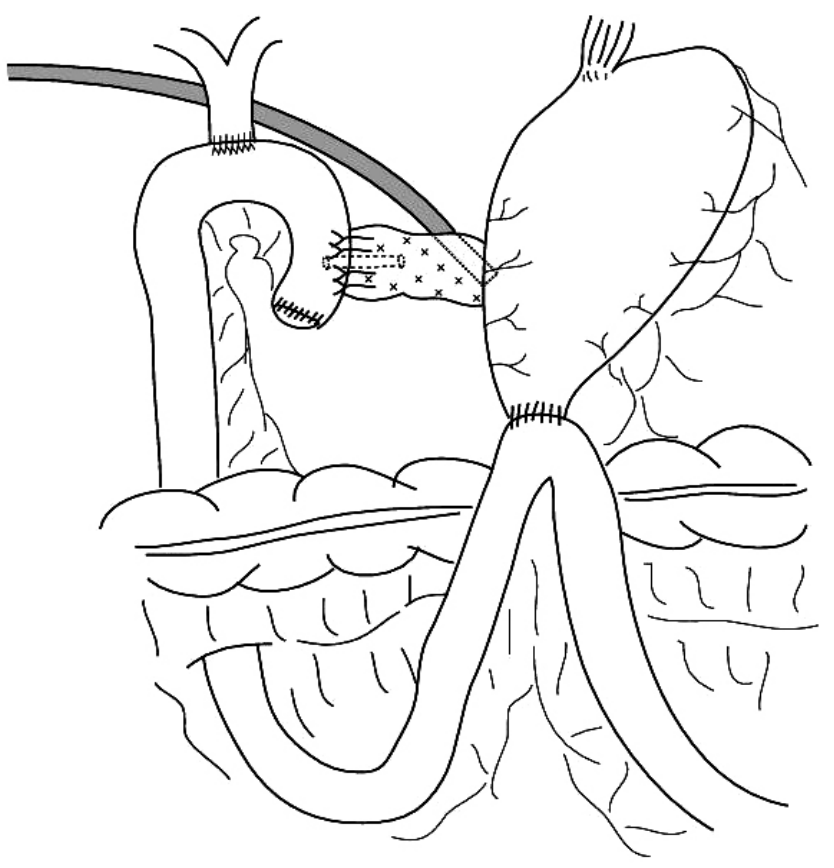

Рис. 1. Схема No-touch пілорусзберігаючої панкреатодуоденальної резекції за Nagai.

У травні 2018 р. пацієнт отримував стаціонарне лікування з приводу наступного клінічного діагнозу - інсулома головки підшлункової залози T2N0M0, II стадія, Ila клінічна група. Гострий післяопераційний панкреатит кукси підшлункової залози. Зовнішня панкреатична нориця. Хронічний гастродуоденіт.

У червні 2018 р. пацієнту було виконано малоінвазивну холецистектомію з приводу гострого каменевого холециститу, після чого стан його покращився

На момент звернення (березень 2019 р.) пацієнт скаржиться на печію, часті запори, які чергуються з проносами, неприємний запах з рота, іноді гіркоту. За даними езофагогастродуоденоскопії виявлено хронічний гастродуоденіт 3 ст. Дуоденогастральний рефлюкс. При УЗД органів черевної порожнини - печінка не збільшена, 172 мм, однорідна, середньозерниста, дещо ущільнена; холедох - 7 мм, портальна вена - 12 мм; жовчний міхур відсутній, у ложі - без особливостей; підшлункова залоза збільшена $21 \times 9 \times 21$ мм, контури чіткі, нерівні, з явищами фіброзу; селезінка не збільшена, 106×35 мм, однорідна, селезінкова вена - 6 мм; надниркові залози - без особливостей; нирки - паренхіма збережена, містять солі 3 мм, ЧМК не розширений, сечоводи не розшире- ні; стінка шлунка 4,7 мм, рихла; кишечник - перистальтика збережена, випоту немає. Було виявлено позитивний антиген на Helicobacter pylori у калі, при дихальному тесті на Helicobacter pyloriрезультат негативний.

При внутрішньошлунковій рH-експрес-діагностиці (табл. 1, рис. 2) отримано висновок про виражену гіпоацидність. Поширення показників $\mathrm{pH}$ у функціональних інтервалах (ФІ) виражене у відсотковому значенні при введенні, виведенні та у загальному підрахунку (результат: домінуючий ФІ 1 вказує на виражену гіпоацидність 70,0 \%). Такий висновок зроблено на тлі наявності дуоденогастроезофагельних рефлюксів і відміни протягом тижня прийому інгібітора протонної помпи пантопразолу (нольпази), яку до цього пацієнт приймав довгий час у дозі 20 мг один раз на добу.

У ході проведення рН-експрес-моніторингу повторне проведення внутрішньошлункової рНметрії (табл. 2, рис. 3) на тлі відміни нольпази протягом одного місяця також показало результат на рівні вираженої гіпоацидності. Поширення показників рН у ФІ виражена у відсотковому значенні при введенні, виведенні та у загальному підрахунку (результат: домінуючий ФІ 1 вказує на виражену гіпоацидність - 57,1\%). 
Огляди літератури, оригінальні дослідження, погляд на проблему, випадок з практики, короткі повідомлення

Таблиця 1. Поширення показників рН у функціональних інтервалах під час першої рН-експрес-діагностики пацієнта $\mathrm{C}$.

\begin{tabular}{|c|c|c|c|}
\hline ФІ рН & $\begin{array}{c}\text { Введення } \\
n-\%\end{array}$ & $\begin{array}{c}\text { Виведення } \\
n-\%\end{array}$ & $\begin{array}{c}\text { Загальне } \\
\mathrm{n}-\%\end{array}$ \\
\hline $5(0.86-1.30)$ & $0-0.0$ & $0-0.0$ & $0-0.0$ \\
\hline $4(1.30-1.60)$ & $0-0.0$ & $0-0.0$ & $0-0.0$ \\
\hline $3(1.60-2.30)$ & $1-5.0$ & $0-0.0$ & $1-2.5$ \\
\hline $2(2.30-3.60)$ & $1-5.0$ & $3-15.0$ & $4-10.0$ \\
\hline $1(3.60-7.00)$ & $18-90.0$ & $10-50.0$ & $28-70.0$ \\
\hline $0(7.00-8.50)$ & $0-0.0$ & $7-35.0$ & $7-17.5$ \\
\hline
\end{tabular}

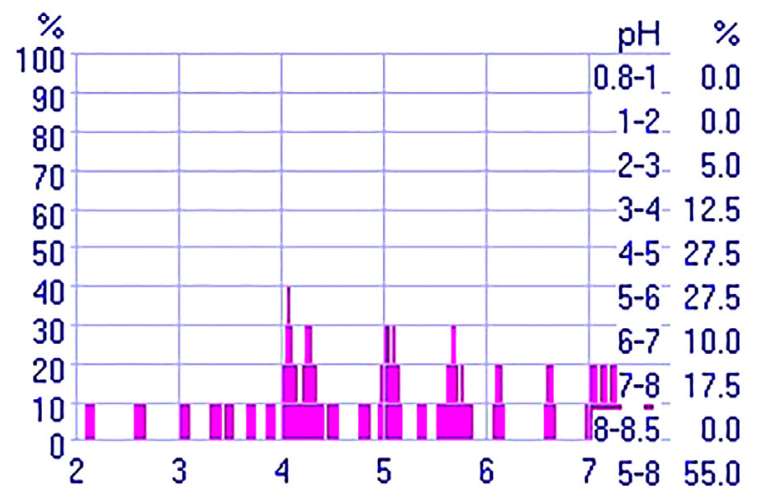

Рис. 2. Динамічне графічне зображення поширеності значень рН у кожному функціональному інтервалі (перша рН-експрес-діагностика пацієнта С.).

Таблиця 2. Поширення показників рН у функціональних інтервалах під час повторної рН-експрес-діагностики пацієнта $C$.

\begin{tabular}{|c|c|c|c|}
\hline ФІ рН & $\begin{array}{c}\text { Введення } \\
n-\%\end{array}$ & $\begin{array}{c}\text { Виведення } \\
n-\%\end{array}$ & $\begin{array}{c}\text { 3агальне } \\
n-\%\end{array}$ \\
\hline $5(0.86-1.30)$ & $0-0.0$ & $0-0.0$ & $0-0.0$ \\
\hline $4(1.30-1.60)$ & $0-0.0$ & $0-0.0$ & $0-0.0$ \\
\hline $3(1.60-2.30)$ & $0-0.0$ & $0-0.0$ & $0-0.0$ \\
\hline $2(2.30-3.60)$ & $12-57.1$ & $7-33.3$ & $23-57.1$ \\
\hline $1(3.60-7.00)$ & $9-47.6$ & $14-71.4$ & $0-2.3$ \\
\hline $0(7.00-8.50)$ & $0-4.7$ & $0-4.7$ & \\
\hline
\end{tabular}

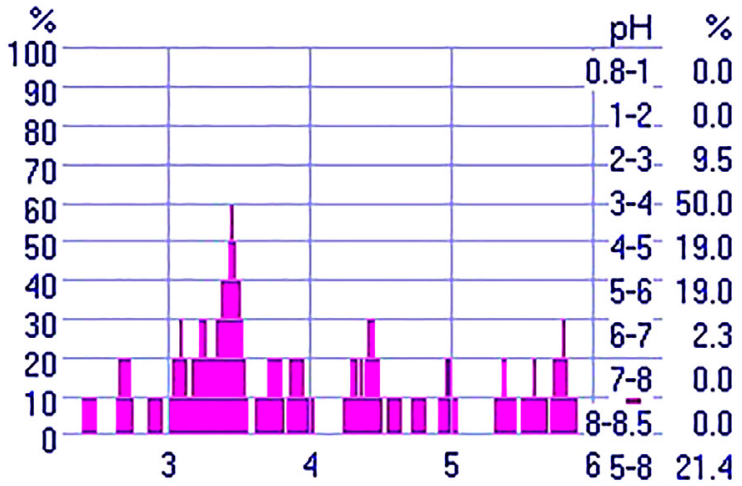

Рис. 3. Динамічне графічне зображення поширення значень $\mathrm{pH}$ у кожному функціональному інтервалі (повторна рН-експрес-діагностика пацієнта С.). 
Огляди літератури, оригінальні дослідження, погляд на проблему, випадок з практики, короткі повідомлення

Про гіпоацидність шлунка свідчать отримані значення домінуючих функціональних інтервалів на які припадає найбільша кількість показників виміру рН в обох обстеженнях. Вони відповідають гіпоацидності шлунка, оскільки із 40 показників внутрішньошлункової експрес-рН-метрії найбільша кількість $\mathrm{pH}$ в обох обстеженнях відповідає першому ФІ (рН від 3,6 до 7,0), що свідчить про виражену гіпоацидність шлунка. Моніторинг показує наявність поступового зниження глибини гіпоацидності шлунка у пацієнта, однак на даний момент рекомендація щодо відміни інгібітора протонної помпи залишається у силі. Стан пацієнта покращився, зменшилась частота чергувань запорів з проносами, хоча ще зберігаються явища порушення випорожнень і періодичної гіркоти у роті.

Для точнішї діагностики і динамічного спостереження рекомендований добовий $\mathrm{pH}$-імпеданс-моніторинг для уточнення секреторної активності шлунка пацієнта і виявлення можливого зв'язку симптомів печії та гіркоти із рефлюксами.

\section{ЛITEPATУРA}

1. Баранов С. А. Поджелудочная железа как единый функционально взаимодействующий орган / С. А. Баранов, В. М. Нечаев // Медицинский совет. 2017. - № 11. - C. 148-151.

2. Ендокринні пухлини підшлункової залози // А. В. Кочатков, А. Г. Крігер, Д. С. Горін, А. Н. Лебедєва / Хірургія. - 2010. - № 9. - С. 19-22.

3. Передерій В. Г. Практична гастроентерологія. Сучасна тактика й алгоритми ведення хворих з основними гастроентерологічними захворюваннями і синдромами : посібник для лікарів / В. Г. Передерій, С. М. Ткач. - Вінниця : Нова Книга, 2012. - 730 с.

\section{REFERENCES}

1. Baranov, S.A., \& Nechayev, V.M. (2017). Podzheludochnaya zheleza kak yedinyy funktsionalno vzayemodeystvuyushchiy organ [The pancreas as a single functionally interacting body]. Meditsinskiy sovet - Medical Council, 11, 148-151 [in Russian].

2. Kochatkov, A.V., Kriher, A.H., Horin, D.S., \& Lebedieva, A.N. (2010). Endokrynni pukhlyny pidshlunkovoi zalozy [Endocrine pancreatic tumors]. Khirurhiia - Surgery, 9, 1922 [in Ukrainian].

3. Perederii, V.H., \& Tkach, S.M. (2012). Praktychna hastroenterolohiia. Suchasna taktyka i alhorytmy vedennia khvorykh z osnovnymy hastroenterolohichnymy zakhvoriuvanniamy i syndromamy: posibnyk dlia likariv [Practical gastroenterology. Modern tactics and algorithms for the management of patients with major gastroenterological diseases and syndromes: a manual for doctors]. Vinnytsia: Nova Knyha [in Ukrainian].
Для визначення доцільності прийому атисекреторної терапії пацієнтом рекомендовані динамічні проведення експрес-рН-метрії.

Висновки. 1. Призначення протокольної терапії у хворих з кислотозалежними захворюваннями навіть при позитивному тесті на Helicobacter pylori потребує додаткового визначення кислотності шляхом виконання внутрішньошлункової рН-експрес діагностики.

2. Аналіз описаного клінічного випадку з виконанням рН-метрії підтвердив вищу діагностичну цінність дихального тесту на Helicobacter pylori, порівняно з виявленням позитивного антигену у калі.

3. Результат виконання рН-метрії у даному клінічному випадку став підґрунтям для відміни антисекреторного препарату пантопразолу.

У перспективі подальших досліджень - вивчення доцільності призначення антисекреторних препаратів за допомогою внутрішньошлункової рН-метрії пацієнтам із коморбідними станами з кислотозалежними захворюваннями.

4. Рациональная диагностика и фармакотерапия заболеваний внутренних органов / 4-е издание, дополненное, под ред. А. Н. Беловол, Г. Д. Фадеенко, О. Я. Бабак. - К. : Здоров'я України, 2015, Т. 1 - 240 с., Т. 2-446 с.

5. Сучасні класифікації та стандарти лікування захворювань внутрішніх органів. Невідкладні стани в терапії / за ред. проф. Ю. М. Мостового. - 23-е вид., доп. і перероб. - К. : Центр ДЗК, 2018-1100 с.

6. Сучасні технології в діагностиці та лікуванні інсуліноми // А. А. Кривко, Г. А. Мельниченко, Н. С. Кузнецов [та ін.] // Проблеми ендокринології. - № 5. - 2013. C. $17-19$.

4. Belovol, A.N., Fadeyenko, G.D., \& Babak, O.Ya. (2015). Ratsionalnaya diagnostika i farmakoterapiya zabolevaniy vnutrennikh organov [Rational diagnosis and pharmacotherapy of diseases of internal organs]. Kyiv: "Zdorovia Ukrainy" [in Russian].

5. Mostovyi, Yu.M. (Ed.). (2018). Suchasni klasyfikatsii ta standarty likuvannia zakhvoriuvan vnutrishnikh orhaniv. Nevidkladni stany $v$ terapii [Modern classifications and standards of treatment of diseases of internal organs. Urgent conditions in therapy]. Kyiv: Tsentr DZK [in Ukrainian].

6. Kryvko, A.A., Melnychenko, H.A., Kuznetsov, N.S., Troshyn, E.A., \& Didiv, I.I. (2013). Suchasni tekhnolohii v diahnostytsi ta likuvanni insulinomy [Modern technologies in the diagnosis and treatment of insulin]. Problemy endokrynolohii-Problems of Endocrinology, 5, 17-19 [in Ukrainian]. 
Огляди літератури, оригінальні дослідження, погляд на проблему, випадок з практики, короткі повідомлення

\title{
ЗНАЧЕНИЕ РН-МЕТРИИ В ДИАГНОСТИКЕ И ФОРМИРОВАНИИ ПЕРСОНИФИЦИРОВАННОГО КОМПЛЕКСНОГО ЛЕЧЕНИЯ ПАЦИЕНТА ПОСЛЕ ПИЛОРУССОХРАНЯЮЩЕЙ ПАНКРЕАТОДУОДЕНАЛЬНОЙ РЕЗЕКЦИИ
}

\author{
๑л. С. Бабинец, И. В. Махницкая, Ю. Я. Коцаба
}

Тернопольский национальный медицинский университет имени И. Я. Горбачевского МОз Украины

РЕЗЮМЕ. Кислотозависимые заболевания составляют значительную часть гастроэнтерологической патологии. Точная диагностика и эффективно подобранная терапия определяют течение заболевания и прогноз пациента. В настоящее время оценка секреторной функции желудка с применением рН-метрии является наиболее информативной и совершенной.

Цель - на клиническом примере продемонстрировать диагностическую ценность использования рН-метрии при кислотозависимых полиморбидных состояниях пациента с целью определения врачебной тактики.

Результаты (клинический случай). Пациент С., 45 лет. Диагноз - инсулома головки поджелудочной железы T2N0M0, II стадия, ІІа клиническая группа, 10.04.2017 г. - атипичная резекция головки поджелудочной железы с инсуломой.

При первичной внутрижелудочной рН-экспресс-диагностике установлена выраженная гипоацидность: имеющийся дуоденогастроезофагельний рефлюкс на фоне недельной отмены ИПП пантопразола, который до этого принимал пациент в дозе 20 мг 1 раз в сутки. Повторное проведение внутрижелудочной рН-метрии на фоне отмены пантопразола в течение 1 мес. также показало результат на уровне выраженной гипоацидности. Однако сравнивая показатели рН-метрии в динамике мы установили постепенное снижение глубины гипоацидности желудка, улучшение общего состояния пациента, уменьшение интенсивности клинической симптоматики.

Выводы. 1. Назначение протокольной терапии больным с кислотозависимыми заболеваниями даже при положительном тесте на H. pylori требует дополнительного определения кислотности путем выполнения внутрижелудочной рН-экспресс диагностики.

2. Анализ данного клинического случая с выполнением рН-метрии подтвердил высокую диагностическую ценность дыхательного теста на Н. pylогі по сравнению с обнаружением положительного антигена в кале.

3. Результат выполнения рН-метрии в данном клиническом случае стал основой для отмены антисекреторного препарата пантопразола.

КЛЮЧЕВЫЕ СЛОВА: инсулома; кислотозависимые состояния; желудок; лечение.

\section{VALUE OF PH-METRIC IN DIAGNOSTICS AND FORMATION OF INDIVIDUAL COMPLEX TREATMENT OF PATIENT AFTER PILOUR SAFE PANCREATODUOODENAL RESECTION}

\author{
@L. S. Babinets, I. V. Mahnitska, Yu. Ya. Kotsaba \\ I. Horbachevskyy Ternopil National Medical University
}

SUMMARY. Acid-dependent diseases constitute a significant part of gastrointestinal diseases. The exact diagnosis and effectively chosen therapy ultimately determine the course of the disease and the patient's prognosis. Currently, evaluation of the secretory function of the stomach using $\mathrm{pH}$-metry is the most informative and perfect.

The aim - to demonstrate the diagnostic value of the use of $\mathrm{pH}$-meter in an acid-dependent polymorbid state of a patient for a clinical specimen in order to determine medical tactics.

Results. Patient S., 45 years old. Diagnosis: pancreatic insulinoma T2N0M0, stage II, clinical group Ila, 10.04.2017 atypical resection of the head of the pancreas with insulinoma.

At the primary intra-gastric pH-express diagnosis, a pronounced hypoacidity was established: an existing duodenogastroiesophagel reflux on the background of a weekly withdrawal of pantoprazole, which was previously taken by the patient at a dose of $20 \mathrm{mg} 1$ time per day. Repeated intra-gastric pH-metry on the background of cancellation of pantoprazole for 1 month also showed the result at the level of severe hypoacidity. However, when comparing the pHmetrics in dynamics, a gradual decrease in the depth of the gipopic acidity, improvement of the general condition of the patient, and a decrease in the intensity of clinical symptoms were established.

Conclusions. 1. Appointment of protocol therapy in patients with acid-dependent diseases, even with a positive test for $\mathrm{H}$. pylori, requires additional determination of acidity by performing intra-gastric $\mathrm{pH}$-express diagnosis.

2. Analysis of this clinical case with the performance of $\mathrm{pH}$-metry confirmed the higher diagnostic value of the respiratory test on $\mathrm{H}$. compared with the detection of a positive antigen in feces.

3. The result of performing $\mathrm{pH}$-metry in this clinical case became the basis for the cancellation of an antisecretory drug pantoprazole.

KEY WORDS: insuloma; acid-dependent states; stomach; treatment.

Отримано 7.05.2019 